
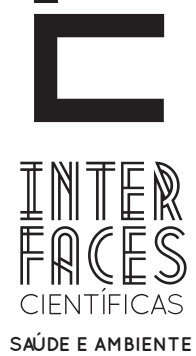

ISSN IMPRESSO 2316-3313

E-ISSN 2316-3798

DOI 10.17564/2316-3798.2016v4n2p29-34

\title{
FREQUÊNCIA DE CASOS POSITIVOS PARA TUBERCULOSE EM TOBIAS BARRETO-SE NO PERÍODO DE 2010-2015
} FREQUENCY OF POSITIVE CASES FOR TUBERCULOSIS IN TOBIAS BARRETO IN THE PERIOD OF 2010-2015 FRECUENCIA DE CASOS POSITIVOS DE TUBERCULOSIS EN TOBIAS BARRETO EN EL PERÍODO 2010-2015

\section{Cleber Santos Silva ${ }^{1}$ \\ Marcela S. de Almeida ${ }^{3}$}

Adélia dos Santos

Rita de Cássia Mendonça de Miranda

\section{RESUMO}

Com objetivo de compreender a frequência de casos positivos para tuberculose em Tobias Barreto-SE, no período de 2010-2015, foi feito levantamento de dados do Sistema de Informação de Agravos e Notificação (SINAN), e a fim de analisar o conhecimento de profissionais que trabalham com a tuberculose foi aplicado questionários. Com efeito, obtemos resultados satisfatórios, concebendo que houve uma variação de 10 e 12 casos por ano, sendo que, em 2014 houve um aumento de casos e a respeito dos questionários os profissionais apresentaram dificuldades em saber o diagnóstico inicial, contudo, conclui-se que o aumento é devido à relação sinérgica da tuberculose com o vírus da imunodeficiência humana e acerca da dificuldade do diagnóstico precoce propõem-se cursos de capacitação para tratar a tuberculose.

\section{PALAVRAS CHAVES}

Sergipe. Tobias Barreto-Sergipe. Saúde Ambiental. Doenças Transmissíveis. Tuberculose. Mycobacterium Tuberculosis. 


\section{ABSTRACT}

Aiming to comprehend the frequency of positive cases of tuberculosis in the city of Tobias Barreto, state of Sergipe, between 2010-2015, it was made a data collection of the Sistema de Informação de Agravos e Notificação (SINAN), and in order to analyze the knowledge of professionals that work with tuberculosis, it was applied a questionnaire, as effect, we obtained satisfactory results, realizing that there was a variation of 10 and 12 cases per year, and in 2014 there was an increase of cases. Regarding the questionnaire, the professionals had difficulty to identify the initial diagnosis, however, it is concluded that the increase is due to the synergistic relation of the tuberculosis with the human immunodeficiency virusand on the difficulty of early diagnosis are proposed training courses for tuberculosis.

\section{KEYWORDS}

Sergipe. Tobias Barreto-Sergipe. Environmental health. Communicable diseases. Tuberculosis. Mycobacterium tuberculosis.

\section{RESUMEN}

Para entender la frecuencia de casos positivos de tuberculosis en Tobias Barreto, SE, en el período 2010-2015, se realizó el Sistema de Informação de Agravos e Notificação (SINAN), para examinar los conocimientos de los profesionales que trabajan en el campo de la salud respiratoria se aplicaron cuestionarios. Obtenemos resultados satisfactorios, percibiendo que hubo una variación de 10 y 12 casos por año y en 2014, un incremento de los casos. Cuanto a los cuestionarios, los profesionales presentan dificultades en conocer el diagnóstico inicial, sin embargo, se concluye que el aumento es debido a la relación sinérgica de la tuberculosis con el virus de inmunodeficiencia humana, y sobre la dificultad de la diagnosis temprana, se proponen cursos de capacitación para tratamiento de la tuberculosis.

\section{PALABRAS CLAVE}

Sergipe. Tobias Barreto-Sergipe. Salud ambiental. Enfermedades transmisibles. Tuberculosis. Mycobacterium tuberculosis. 


\section{INTRODUÇ̃̃O}

A Tuberculose (TB) é uma patologia microbiana que pode ter matado mais pessoas do que qualquer outra. Segundo a Organização Mundial de Saúde (OMS, 2014), a TB é uma das doenças infecciosas que mais mata no mundo, afetando principalmente populações de baixa renda, estando associada principalmente à falta de higiene e má alimentação. De acordo com Piller (2012), em países desenvolvidos os mais atingidos são as pessoas idosas e a população de imigrantes. A OMS estima que a disseminação do Vírus da Imunodeficiência Humana (HIV) tem aumentado à probabilidade das pessoas de desenvolverem a TB.

Um terço da população mundial está infectado e, a cada ano, 9 milhões de casos novos é registrado no mundo (equivalente a 126 casos por 100.000 habitantes) resultando na morte de 1,5 milhão, todo ano, afirma a OMS (2014). Conforme o Programa Nacional de Controle da Tuberculose (2006), o Brasil está ocupando $014^{\circ}$ lugar entre os 22 países com alto índice de casos no mundo e cerca de 110 mil casos novos são registrados no Brasil, com cerca de 6.000 óbitos/ano. De acordo com Hijjar e outros autores (2005), os estados de São Paulo, Rio de Janeiro, Bahia, Minas Gerais, Rio Grande do Sul e Pernambuco apresentam maiores notificações de casos. Em 1999, o estado de Sergipe apresentou 340 casos de tuberculose.

A TB também é prioridade do Ministério da Saúde do Brasil desde 2003 e foi a principal causa de mortes até o início do século XX. Em 1993 a Tuberculose foi considerada uma emergência mundial pela OMS. A mesma com parceria com a Stop TB estipulou a redução de casos pela metade até 2015 e erradicada até 2050 em comparação a 1990.

A TB é um problema mundial de saúde. Não obstante, a tuberculose é uma doença curável quando há o diagnóstico e o tratamento mais rápido possível, medida importante para salvar a vida e recuperar os enfermos. Por isso é importante compreender os poucos casos notificados dessa enfermidade.

Diante de tudo aqui relatado é de suma importância que se pesquisa e notifique casos de tuberculose nos diferentes municípios dos diversos estados do Brasil.

\section{MÉTODO}

\subsection{TIPO E LOCAL DE ESTUDO}

Trata-se de um estudo documental, quantitativo cujo objetivo foi analisar a frequência da tuberculose no Município de Tobias Barreto, Sergipe, Brasil.

\subsection{POPULACÃO E AMOSTRAGEM}

O presente estudo consistiu na consulta no Sistema de Informação de Agravos e Notificação (SINAN) da Secretaria de Saúde da cidade de Tobias Barreto- SE, sobre os pacientes que fizeram o exame de baciloscopia no período de janeiro de 2010 a setembro de 2015.

\subsection{INTERCORRÊNCIA}

A fim de avaliar o conhecimento desses profissionais no âmbito das doenças infecciosas, especificamente da tuberculose foram aplicados questionários a dez profissionais de saúde, entre dois médicos, quatro enfermeiros, um biólogo, dois biomédicos e um fisioterapeuta da cidade de Tobias Barreto-SE. Como critério para seleção desses profissionais, buscamos ouvir os que trabalham com pacientes positivos para tuberculose.

\subsection{PROCEDIMENTO ÉTICO}

A realização deste estudo considerou a Resolução n 196/96 do Conselho Nacional de Saúde que rege sobre a ética da pesquisa, envolvendo seres humanos direta ou indiretamente, assegurando a garantia de que a 
privacidade do sujeito da pesquisa foi preservada. Este projeto foi submetido ao Comitê de Ética em Pesquisa.

\subsection{ANÁLISE ESTATÍSTICA}

Com o objetivo de avaliar se ocorreu diferença estatística significativa entre os dados encontrados, foi realizada uma análise de variância (Test $t$-Student) dos dados encontrados com o auxílio do Software Statistic 6.0.

\section{RESULTADOS}

O número de casos positivos para tuberculose no município de Tobias Barreto-SE, entre os anos de 2010 e 2015, pode ser observado na Figura 1. Durante os cinco anos analisados observa-se que houve uma constância no número de casos variando entre 10 e 12 casos/ano. Porém, no ano de 2014 houve um aumento no número de casos positivos para TB no município, notando-se também que o dobro dos casos são homens.

Figura 1 - Número de casos positivos de tuberculose pulmonar (TB) no município de Tobias Barreto - SE nos anos de 2010 a 2015

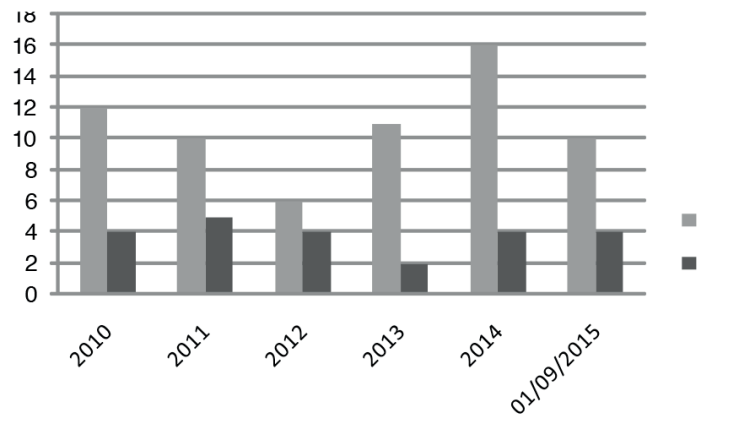

Fonte: SINAN

Constatou-se que $100 \%$ dos profissionais entrevistados estavam bem informados quanto à etiologia da doença, forma de tratamento, agente causador e sintomatologia. Entretanto, constata-se que ainda existe entre os profissionais de saúde que se encontram na primeira linha de diagnóstico, uma dificuldade em detectar de forma precisa a doença.
Outro ponto que também deve ser considerado, são os casos de resistência bacteriana que vem surgindo ao longo dos anos. Pelo fato do tratamento da tuberculose ser longo e, muitas vezes complicado devido aos efeitos colaterais da antibioticoterapia, muitos pacientes param de tomar a medicação com o desaparecimento dos sintomas o que torna a Mycobacterium tuberculosis resistente à química de escoIha. Após uma análise constatou-se que houve diferença estatística significativa entre os anos de $2014 \mathrm{e}$ os demais anos estudados com $p=0,03$.

\section{DISCUSSÃO}

De acordo com Rufino-Neto (2002), o estado de Sergipe apresenta uma incidência de casos positivos de tuberculose de 34,8 casos $/ 1000.00$ habitantes. 0 que é uma incidência preocupante, levando em consideração a extensão geográfica do estado sendo o menor do país. Oliveira Junior e outros autores (2015) relataram uma alta incidência de casos de tuberculose em Palmas-TO e atribuíram essa situação ao aumento de casos de HIV positivo no município.

Silva e outros autores (2014), após análises dos prontuários, observou uma baixa incidência nos casos de tuberculoses na região do vale do Piancó-PB. Os autores relataram que das 49 amostras analisadas no ano de 2009, apenas uma deu positivo. Ao contrário do que este trabalho apresentou.

Lopes e outros autores (2015) relatam que a dificuldade em diagnosticar a doença está no fato da confusão dos sintomas iniciais com outras infecções bacterianas ou até mesmo viroses. No mesmo trabalho também é relatado que a falta de vínculo do profissional com o paciente, devido à rotatividade dos profissionais nos serviços de saúde, prejudica uma melhor abordagem desse paciente.

De acordo com Rocha e outros autores (2015), é de suma importância a farmacovigilância nos tratamen- 
tos de tuberculoses, pois não é rara a desistência do tratamento por parte do paciente. Isto se deve principalmente à administração de várias drogas, entre elas antibiótico, antirretrovirais e hipoglicemiantes.

\section{ESTUDO TEÓRICO}

A tuberculose é causada por uma bactéria denominada Mycobacterium tuberculosis (Mtb), também chamado de bacilo de Koch em homenagem à descoberta por Robert Koch em 1882. A Mtb tem como principais características ser resistente à dessecação, à temperatura baixa e a agentes químicos, mas sensível à luz solar (COELHO; MARQUES, 2006; TORTORA, 2012), sua resistência provém da parede celular rica em lipídios e elevadas proporções de guanina e citosina. Os sintomas causados são febre, tosse de três semanas ou mais, catarro com sangue e perda de peso. A cada $\mathrm{mL}$ de escarro um bacilífero elimina cinco mil bacilos aproximadamente, o que caracteriza como a maior fonte de infecção.

Há também a tuberculose latente, no qual o hospedeiro não apresenta sintomas, isto é, assintomática, o que não se considera uma doença infecciosa, mas tendo mais chance de desenvolver a doença.

Outra espécie de micobactéria que causa TB é a Mycobacterium bovis. Esta espécie causa tuberculose principalmente em gados e raramente em humanos por meio de alimentos contaminados (TORTORA, 2012).

Conforme Trabulsi \& Alterthum (2004), o diagnóstico mais utilizado é o exame de baciloscopia do escarro, isto é, o método bacilo álcool-ácido resistente (BAAR), mas também pode ser usado o teste de tuberculina (PPD) onde é possível detectar a doença antiga ou recente e detectar a TB latente. O tratamento básico tem duração de seis meses, baseado nos remédios em um "pool" de antibióticos.

Uma forma importante de prevenir a doença é a profilaxia, Tortora (2012), destaca que a vacina BCG contra a tuberculose é feita a partir da diminuição da virulência da $M$. bovis, e é uma das vacinas mais usadas do mundo, porém, há objeções quanto ao uso dela devido sua baixa eficácia em adolescentes e adultos, além de causar uma infecção fatal em crianças com HIV a partir da BCG. Devido a essa característica da vacina, alguns autores contestam sua eficiência.

A TB apareceu pela primeira vez na literatura grega como tísica (do grego "phthisis" que significa definhar) e era quase sempre fatal. Cerca de 460 a.C., Hipócrates identificava a tísica como a doença mais difundida dos tempos. Aristóteles (384-322 a.C.) acreditava que a doença era contagiosa, mas alguns autores gregos achavam que seria hereditaria. Clarissimus Galeno (131-201 d.C.), melhor médico depois de Hipócrates definia tísica como uma úlcera nos pulmões e garganta acompanhada de tosse, febre e pus, descrevendo-a como doença da desnutrição (PALOMINO ET AL., 2007).

Há hipótese que o gênero Mycobacterium surgiu a mais que 150 milhões atrás, mas estudo de genética molecular e sequenciamento de genoma concluiu que a M. tuberculosis esteve presente na África Oriental há 3 milhões de anos atrás e sugerem que tenha infectado os primeiros hominídeos daquele tempo (DANIEL, 2006).

Koch (1890) alega que as bactérias se proliferam mais subitamente em ambiente úmido e que podem ser transportadas pelo ar, mas neste não podem se proliferar.

\section{CONCLUSÃO}

Diante do que foi avaliado, os resultados foram alcançados pode-se observar que os casos positivos para tuberculose aumentaram ao longo dos anos e que isto pode estar relacionado com as condições socioeconômicas, além da ação sinérgica com o HIV. Observou-se, também, que embora os profissionais 
de saúde se mostrem bem informados quanto à tuberculose ainda é complicado o diagnóstico precoce da doença por parte desses profissionais.

Neste âmbito, os autores propõem que seja preparado e ministrado pela Faculdades Integradas de Sergipe (FISE) junto à Secretaria do Município de Tobias Barreto-SE, um curso de capacitação frente a doenças infecto-contagiosas com enfoque na tuberculose.

\section{REFERÊNCIAS}

\section{COELHO, F.; MARQUES, E. Etiologia. Revista} Hospital Universitário Pedro Ernesto, v.5, n.2, Rio de Janeiro, 2006. p.24-26

DANIEL, T. M. The history of tuberculosis. Respiratory Medicine, v.100, n.11, 2006. p.1862-1870,

HIJJAR, M. A.; PROCÓPIO, M. J.; FREITAS, L. M. R. Epidemiologia da tuberculose: importância no mundo, no Brasil e no Rio de Janeiro. Cidade: Instituto de Doenças do Tórax, 2005.

$\mathrm{KOCH}, \mathrm{R}$. Ueber bakteriologische Forschung: vortrag in der 1. allgemeinen Sitzung des X. Internationalen Medicinischen Congresses am 4. 1890. p.650-660.

LOPES, L. M. G.; VIEIRA, N. F.; LANA, F. C. F. Análise dos Atributos da Atenção Primária à Saúde na
Atenção à Tuberculose no Brasil: Uma Revisão Integrativa. R. Enferm. Cent. O. Min. v.5, n.2, Belo Horizonte-MG, maio-ago. 2015. p.1684-1703.

OLIVEIRA JR, H. S; MENDES, D. H. C; ALMEIDA, R. B. Prevalência de Casos de Tuberculose durante os Anos de 2002 a 2012, no Município de PalmasParaná, Brasil. Rev. Saúde Públ. Santa Cat., v.8, n.1, Florianópolis-SC, jan-abr. 2015. p.43-57.

PILLER, Raquel V. B. Epidemiologia da tuberculose, v.21, n.1, Rio de Janeiro, 2012. p.4-9.

ROCHA, J. L. et al. Farmacovigilância em tuberculose: relato de uma experiência no Brasil. Vigil. sanit. Debate, v.3, n.2, Brasília, 2015. p.131-135.

RUFFINO-NETTO, A. Tuberculose: a calamidade negligenciada. Revista da Sociedade Brasileira de Medicina Tropical, v.35, n.1, Brasília, 2002. p.51-58.

SILVA, G. A. et al. Levantamento da incidência de tuberculose na região do vale do Piancó-PB. Revista Verde de Agroecologia e Desenvolvimento Sustentável, v.8, n.2, Pombal-PB, 2014. p.8-11.

TORTORA, G. J.; BERDELL, R.F.; CHRISTINE, L.C. Microbiologia, 10.ed., 2012. 964p.

TRABULSI, L. R. et al. Microbiologia, 3.ed. São Paulo: Atheneu, 2000. 